\title{
Papel de los flavonoides del té en la protección cardiovascular
}

de Luis DA, Aller R. Papel de los flavonoides del té en la protección cardiovascular. An Med Interna (Madrid) 2008; 25: $105-107$.

\section{INTRODUCCIÓN}

Los flavonoides son un ejemplo de compuestos antioxidantes naturales, que están ampliamente distribuidos en los alimentos vegetales presentes en la dieta normal humana. La evidencia epidemiológica sugiere que los flavonoides dietéticos podrían ejercer efectos protectores en las enfermedades cardiovasculares como la enfermedad cardiaca o el infarto mediante mecanismos antiaterogénicos, antioxidantes, antiagregantes, vasodilatadores y antihipertensivos. Una de las mayores fuentes dietéticas de flavonoides en la población mundial es el té, que contiene mayoritariamente catequinas, un tipo especial de flavonoides.

Los flavonoides son un amplio grupo de compuestos polifenólicos de bajo peso molecular, que tienen en común el esqueleto 2-fenilcromano (C6-C3-C6). Esta estructura base puede presentar muchas sustituciones y variaciones que dan lugar a los diversos tipos de flavonoides: flavonoles, flavonas, flavanonas, catequinas, antocianos, isoflavonas y chalconas. Se han identificado más de 4000 flavonoides diferentes, y se estima que pueda haber más. Las fuentes dietéticas principales son las cebollas, vino, manzanas, uvas y el té (1).

El té (obtenido a partir de las hojas de la especie Camellia sinensis) es una de las bebidas más antiguas, y es la segunda más consumida por detrás del agua. Aunque existen muchas variedades, es el té verde el que contiene mayor cantidad de derivados polifenólicos gracias a su método de fabricación: las hojas no son sometidas a un proceso de fermentación, por lo que contienen mayor cantidad de antioxidantes. De los polifenoles totales del té, el 59,9\% lo constituyen las catequinas. Las catequinas (flavanoles) tienen dos núcleos fenólicos (A y B) que están unidos por tres átomos de carbono que forman parte, junto con un átomo de oxígeno, del anillo C. Los carbonos 2 y 3 del anillo C son asimétricos y según la posición espacial de los sustituyentes del C3, las catequinas pueden ser enantiómeros (+) o (-). Se han definido ocho catequinas diferentes, siendo las mayoritarias el ()-galato de epigalocatequina (EGCG) y (+)-galocatequina (GC), que representan el 51,8\% de las ocho catequinas (2).

La composición del té puede variar según la especie, el medio de cultivo, la estación del año y edad de la planta. Por ejemplo, en el té verde las catequinas representan un 80-90\% de los flavonoides, mientras que en el té negro esta proporción es de $20-30 \%$. En general, las hojas más jóvenes tienen menos catequinas. La forma de preparar la infusión también influye, ya que temperaturas elevadas producen una disminución de la concentración de catequinas, por lo que es preferible dejar enfriar el agua antes de introducir las hojas del té. Las catequinas del té verde son solubles en agua, por lo que el grado de extracción de éstas depende del tiempo de contacto de las hojas con el agua.

En cuanto a la biodisponibilidad de las catequinas, diversos estudios señalan que la leche que en ocasiones es añadida al té, contrarresta los efectos saludables de las catequinas, probablemente porque la caseína de la leche quelan las catequizas, sin embargo los resultados son contradictorios (3).

\section{MECANISMOS DE ACCIÓN EN LA PROTECCIÓN CARDIOVASCULAR}

Los mecanismos implicados en la posible acción beneficiosa de los flavonoides del té sobre el riesgo cardiovascular, pueden estar relacionados con sus propiedades antioxidantes (inhibición de la oxidación de las LDL), con la inhibición de la agregación plaquetaria, con la modulación de la función endotelial y con propiedades antihipertensivas $(4,5)$.

La oxidación de las LDL es uno de los factores clave en la patogénesis de la ateroesclerosis. Las células endoteliales, las del músculo liso y los macrófagos producen radicales libres y favorecen la oxidación de las LDL. Las LDL oxidadas son agentes quimiotácticos para macrófagos y monocitos, originando su acumulación en la íntima. Existe evidencia experimental de que ciertos antioxidantes (como las catequinas y flavonoles del té) inhiben la formación de las células espumosas y ralentizan la progresión de la ateroesclerosis (6). Los flavonoides pueden impedir la generación de radicales libres y/o neutralizar al anión superóxido, el radical hidroxilo y el radical lipoperoxido. Estas propiedades antioxidantes previenen la oxidación de las LDL, lo que podría explicar los efectos protectores de los flavonoides en las enfermedades cardiovasculares.

Los polifenoles son los antioxidantes más abundantes de la dieta. Su ingesta es 10 veces mayor que la de vitamina $\mathrm{C} \mathrm{y}$ 100 veces mayor que la de vitamina E o carotenoides. Algunos flavonoides, como la catequina y la quercetina pueden 
captar directamente especies reactivas de oxígeno (ROS), como superóxido $\left(\mathrm{O}_{2}-\right)$, agua oxigenada $\left(\mathrm{H}_{2} \mathrm{O}_{2}\right)$ o ácido hipocloroso $(\mathrm{HOCl})$, que pueden ser muy dañinos para lípidos, proteínas y DNA. Los flavonoides actúan fundamentalmente como tampones, capturando radicales libres con formación del radical flavínico, mucho menos reactivo ya que los electrones desapareados están más deslocalizados (Fig. 1A). Los flavonoides también pueden quelar iones metálicos de transición (hierro y cobre), lo que evitaría la formación de ROS obtenidos por la reacción de Fenton (Fig. 1B).

(A)<smiles>Oc1ccccc1O</smiles>
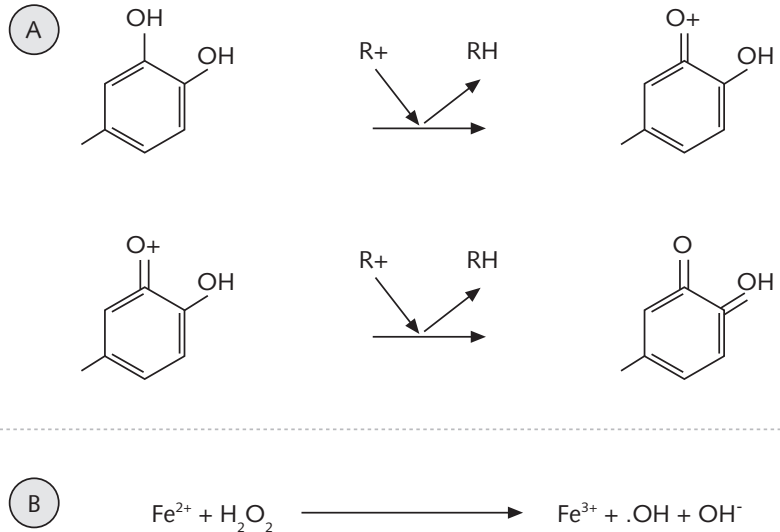

$$
\begin{aligned}
& \mathrm{Fe}^{2+}+\mathrm{H}_{2} \mathrm{O}_{2} \longrightarrow \mathrm{Fe}^{3+}+. \mathrm{OH}+\mathrm{OH}^{-} \\
& \mathrm{Fe}^{3+}+\mathrm{H}_{2} \mathrm{O}_{2} \longrightarrow \mathrm{Fe}^{2+}+. \mathrm{OOH}+\mathrm{OH}^{+}
\end{aligned}
$$

Fig. 1. Capturación de radicales con formación de radical flavínico $(A) ;$ Quelación de hierro por flavonoides (B).

En contraste con los efectos inhibitorios de los flavonoides frente a la oxidación de las LDL in vitro, la ingestión de los flavonoides con la dieta no ha demostrado claramente la protección de la oxidación de las LDL in vivo, existiendo resultados contradictorios en este sentido. Se cree que es posible que en el efecto preventivo de los flavonoides en el desarrollo de ateroesclerosis pueden estar implicados otros mecanismos que actuando sinérgicamente pudieran justificar la protección de la mortalidad cardiovascular constatada en los ensayos epidemiológicos (2).

El siguiente mecanismo de acción implicado en la prevención cardiovascular es la modulación de la función endotelial. Duffy y cols., (7) analizaron la reversión de la disfunción endotelial en un estudio cruzado con 66 sujetos con enfermedad cardiovascular, a los que se les hace consumir té negro (diariamente cuatro tazas -900 ml- de té negro) o agua como placebo. Los resultados indicaron que el consumo de té negro a corto ( 2 horas después de ingerir 2 tazas de té o de agua) y a largo plazo (4 semanas después de ingerir las 4 tazas diariamente) mejoraba la función endotelial y, por tanto, la dilatación y contracción de los vasos sanguíneos, lo que ayuda a reducir el riesgo de ataques cardiacos. Este resultado positivo no se observó en las personas que bebían agua, ni tampoco al suministrar a los pacientes una dosis oral de $200 \mathrm{mg}$ de cafeína, lo que indica que los efectos se deben a los flavonoides del té.

Otros grupos también han evaluado la acción sobre la función endotelial del consumo de té. Kim y cols., (8) investigaron el efecto a corto plazo del consumo de té verde $(8 \mathrm{~g} /$ día durante 2 semanas) por fumadores crónicos en la función endotelial y en las células progenitoras endoteliales. Los resultados mostra- ron que el número de dichas células circulantes estaba inversamente relacionado con el hábito tabáquico y la disfunción endotelial. La administración de té verde indujo un rápido aumento de los niveles de células progenitoras endoteliales y una mejora de dilatación vascular dependiente de endotelio, por tanto este mecanismo de acción del té puede jugar un papel importante en la prevención cardiovascular (9).

Otro posible mecanismo de acción beneficioso de los flavonoides del té es su actuación sobre la quimiotáxis y la producción de moléculas de adhesión. Se ha sugerido que la ateroesclerosis es un proceso inflamatorio crónico. El reclutamiento de leucocitos mononucleares y la formación de lesiones ricas en macrófagos en la íntima, en sitios específicos de las arterias, son clave en la aterogénesis. Por tanto, las alteraciones en las propiedades quimiotácticas y adhesivas del endotelio juegan un importante papel en dicho proceso. Los resultados de los estudios sobre estas propiedades de los polifenoles del té muestran que las teaflavinas inhiben, de forma significativa, la adhesión de los monocitos a las células endoteliales, y la expresión de moléculas de adhesión intercelular (ICAM-1) y moléculas de adhesión endotelial (VCAM-1), lo que explicaría en parte las propiedades antiaterogénicas del té (10).

Las plaquetas tienen una función muy importante en el proceso de coagulación: interaccionando con la red de fibrina, liberan mediadores que aceleran la coagulación, y aumentan la retracción del coágulo sanguíneo. Debido a su papel en la formación de trombos (es necesario la activación y agregación de las plaquetas). Se han descrito diferentes mecanismos por los que los flavonoides inducen la inhibición de la agregación plaquetaria, dependiendo del tipo y estructura del flavonoide: quercetina, fisetina, kaempferol, miricetina, etc, que se encuentran en diferentes fuentes alimentarias.

Un mecanismo esencial para que se origine la agregación plaquetaria es el aumento de calcio en el interior de la plaqueta. El ionóforo de calcio A23187 aumenta el flujo de calcio hacia el interior de la plaqueta aumentando así la concentración de calcio intraplaquetario. Este aumento implica la formación de diferentes endoperóxidos y a la fosforilación de varias proteínas necesarias para la agregación. Dicho ionóforo es inhibido por la EGCG del té verde, lo que conduce a una disminución del Ca2+ en el interior de la plaqueta. Esta disminución trae como consecuencias una inhibición de la formación del inositol trifosfato (IP3), una inhibición de la unión del fibrinógeno a su receptor plaquetario IIb/IIIa, y posiblemente un descenso del tromboxano A2 (TXA2) y de la prostaglandina F2 $\alpha$ (PGF2 $\alpha$ ), impidiendo todo ello la agregación plaquetaria. Otro mecanismo proagregante consiste en la fosforilación inducida por la trombina de residuos de tiroxina de proteínas quinasas de las plaquetas. La activación de las proteín quinasas conduce a la fosforilación de proteínas que son necesarias para la activación de la fosfolipasa $\mathrm{C}$, que regula el aumento de calcio intracelular y la activación de la proteín quinasa $\mathrm{C}$, que es necesaria a su vez para la expresión del receptor IIb/IIIa del fibrinógeno. Distintos estudios han encontrado una inhibición de la activación de las proteín quinasas por los flavonoides del té, lo que conduce a un efecto antiagregante de las plaquetas (11).

Sin embargo en el estudio de Duffy y cols., (12) donde se analiza el efecto del consumo agudo y crónico de té negro en la agregación plaquetaria de 49 pacientes con enfermedad cardiovascular, los resultados obtenidos demuestran que la agregación plaquetaria ex vivo, en respuesta al ADP y al péptido activador del receptor de la trombina, no se modifica por el 
consumo de té, a pesar de la adecuada absorción de los flavonoides, como evidencia el incremento en los niveles de catequinas plasmáticas. Estos autores sugieren que el efecto protector de los alimentos que contienen flavonoides debe estar mediado por su actuación sobre otros factores de riesgo diferentes a la agregación plaquetaria.

Por último es necesario revisar el efecto sobre la tensión arterial de estas moléculas. Aunque existen varios estudios sobre los efectos antihipertensivos del flavonoide más abundante en la dieta, la quercetina, existen escasos estudios de los efectos del consumo de té sobre la presión arterial. En este sentido, se ha comprobado en un estudio realizado en 218 mujeres de edad avanzada que la presión arterial sistólica disminuía $2,2 \mathrm{mmHg}$, y la diastólica $0,9 \mathrm{mmHg}$ tras el consumo de una taza de té. Estos resultados indican que un consumo regular a largo plazo podría tener efectos favorables sobre la presión arterial (13).

\section{ESTUDIOS DE EPIDEMIOLÓGICOS}

Los estudios que evalúan el efecto del consumo del té sobre el riesgo cardiovascular en humanos son escasos. El primer estudio fue el Rotterdam Study (14), donde se analizaba la asociación entre la ingesta de té y el riesgo de ateroesclerosis en la población general (3454 sujetos sanos, de ambos sexos mayores de 55 años). El resultado fue una asociación inversa y significativa entre la ingesta de té y la aparición de ateroesclerosis severa en la aorta (la asociación con la ateroesclerosis moderada no fue estadísticamente significativa). Este estudio mostró un efecto protector del té contra las cardiopatías isquémicas.

El Zutphen Elderly Study (15) evaluó la asociación entre el consumo de catequinas (del té, pero también de otras fuentes alimentarias) y la incidencia y mortalidad de cardiopatías isquémicas e infartos cerebrales. Las conclusiones de este tra- bajo fueron que las catequinas pueden reducir el riesgo de morir por cardiopatía isquémica, pero no por infarto cerebral.

Kenneth y cols., (16) analizaron la relación entre el consumo de té y la mortalidad después de un infarto agudo de miocardio. Se constató que el consumo de té durante el año anterior al infarto estaba asociado con una menor mortalidad después del infarto.

Por el contrario, en el Caerphilly Study (17) (en el que el mayor consumo de flavonoides fue como té con leche) constatan un incremento no significativo de enfermedad cardiovascular y un aumento significativo de la mortalidad total entre los quartiles más altos de flavonoides comparados con los más bajos. Sus autores hipotetizan que este resultado negativo puede deberse a que la cantidad de flavonoides ingeridos sería muy baja debido a que éstos podrían precipitar con las proteínas de le leche añadida al té, con lo que su absorción oral disminuye. Este efecto negativo de la leche sobre los efectos cardiovasculares positivos de los flavonoides del té, se ha estudiado también en pacientes sanos (18).

En conclusión, los estudios revisados sugieren que un consumo habitual de té (unas 4 tazas diarias) sería de ayuda para la prevención de enfermedades cardiovasculares, siempre en el contexto de una dieta equilibrada y actividad física adecuada. No obstante, los beneficios a nivel molecular que los flavonoides del té pueden aportar sobre la salud cardiovascular, deben ser evaluados en estudios de intervención, siendo necesarios nuevos ensayos clínicos para evaluar de manera eficaz la respuesta a diferentes dosis de flavonoides provenientes del té.

\section{A. DE LUIS, R. ALLER}

Sección de Endocrinología y Nutrición Clínica. Unidad de Apoyo a la Investigación. Hospital Universitario del Río Hortega. Instituto de Endocrinología y Nutrición Clínica. Facultad de Medicina de Valladolid

\section{Bibliografía}

1. Graham NH. Green tea composition, consumption, and polyphenol chemistry. Prev Med 1992; 21: 334-50.

2. Williamson $\mathrm{G}$, Manach $\mathrm{Cl}$. Bioavailability and bioefficacy of polyphenols in humans. II. Review of 93 intervention studies. Am J Clin Nutr 2005; 81: 243S-255.

3. Reddy VC, Vidya Sagar GV, Sreeramulu D, Venu L, Raghunath M. Addition of milk does not alter the antioxidant activity of black tea. 2005; 49 (3): 189-95.

4. Riemersma RA, Rice-Evans CA, Tyrrell RM, Clifford MN. Lean MEJ. Tea flavonoids and cardiovascular health. Q J M 2001; 94: 277-82.

5. Tamba Y, Ohba S, Kubota M, Yoshioka H, Yoshioka H, Yamazaki M. Single GUV Method Reveals Interaction of Tea Catechin (-)-Epigallocatechin Gallate with Lipid Membranes. Biophys J 2007; 106: 97-105.

6. Jessup W, Rankin SM, De Whalley CV, Hoult JR, Scott J, Leake DS. Alpha-tocopherol consumption during low-density-lipoprotein oxidation. Biochem J 1990; 265: 399-405.

7. Duffy SJ, Keaney JF, Holbrook M, Gokce N, Swerdloff PL, Frei B, Vita JA. Short- and Long-Term Black Tea Consumption Reverses Endothelial Dysfunction in Patients With Coronary Artery. Dis Circulation 2001; 104: 151-6.

8. Kim W, Ho Jeong M, Hee Cho S, Hye Yun J, Jae Chae H, Keun Ahn Y, et al. Effect of Green Tea Consumption on Endothelial Function and Circulating Endothelial Progenitor Cells in Chronic Smokers. Circ J 2006; 70: 1052-7.

9. Hodgson JM. Effects of tea and tea flavonoids on endothelial function and blood pressure: A brief review. Clin Exp Pharmacol Physiol 2006; 33: $838-841$.

10. Stangl V, Dreger H, Stangl K, Lorenz M. Molecular targets of tea polyphenols in the cardiovascular system. Cardiovasc Res 2007; 73: 348-58.

11. Holt RR, Actis-Goretta L, Momma TY, Keen CL. Dietary flavanols and platelet reactivity. J Cardiovasc Pharmacol 2006; 47: S187-96.

12. Duffy SJ, Vita JA, Holbrook M, Swerdloff PL, Keaney JF. Effect of acute and chronic tea consumption on platelet aggregation in patients with coronary artery disease. Arterioscler Thromb Vasc Biol 2001: 21; 1084-9.

13. Hodgson JM, Puddey IB, Burke V, Beilin LJ, Jordan N. Effects on blood pressure of drinking green and black tea. J Hypertension 1999; 17: 457-63.

14. Geleijnse JM, Launer LJ, Hofman A, Pols HA, Witteman JC. Tea flavonoids may protect against atherosclerosis: the Rotterdam Study. Arch Intern Med 1999; 159: 2170-4.

15. Arts A, Ilja CW, Hollman P, Feskens CH, Edith JM, Bueno de Mesquita $\mathrm{H}$, et al. Catechin intake might explain the inverse relation between tea consumption and ischemic heart disease: the Zutphen Elderly Study. Am J Clin Nutr 2001: 74; 227-32.

16. Mukamal KJ, Maclure M, Muller JE, Sherwood JB, Mittleman MA. Tea Consumption and Mortality After Acute Myocardial Infarction. Circulation 2002; 105: 2476-81.

17. Hertog MG, Sweetnam PM, Fehily AM, Elwood PC, Kromhout D. Antioxidant flavonols and ischemic heart disease in a Welsh population of men: The Caerphilly Study. Am J Clin Nutr 1997; 65: 1489-94.

18. Lorenz M, Jochmann N, von Krosigk A, AMrtus P, Baumann G, Stangl $\mathrm{K}$, et al. Addition of milk prevents vascular protective effects of tea. Eur Heart J 2007; 28: 219-23. 